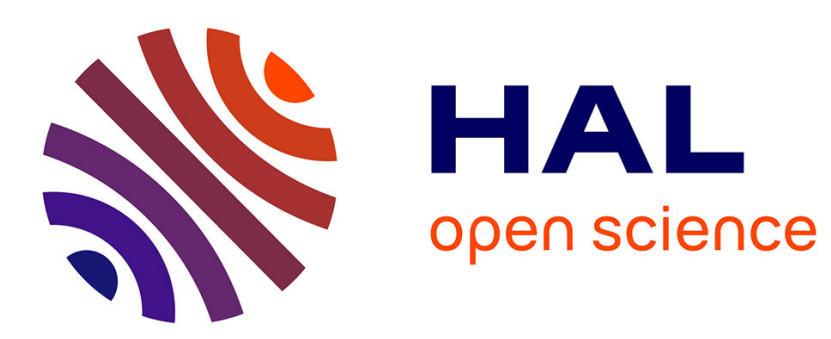

\title{
Characterization of MHD convection in thin cell electrodeposition
}

Carolina Cronemberger, Rafik Ballou, Pierre Molho

\section{To cite this version:}

Carolina Cronemberger, Rafik Ballou, Pierre Molho. Characterization of MHD convection in thin cell electrodeposition. Magnetohydrodynamics c/c of Magnitnaia Gidrodinamika, 2009, 45, pp.3-8. 10.22364/mhd.45.2.15 . hal-00963906

\section{HAL Id: hal-00963906 https://hal.science/hal-00963906}

Submitted on 6 Oct 2020

HAL is a multi-disciplinary open access archive for the deposit and dissemination of scientific research documents, whether they are published or not. The documents may come from teaching and research institutions in France or abroad, or from public or private research centers.
L'archive ouverte pluridisciplinaire HAL, est destinée au dépôt et à la diffusion de documents scientifiques de niveau recherche, publiés ou non, émanant des établissements d'enseignement et de recherche français ou étrangers, des laboratoires publics ou privés. 


\title{
CHARACTERIZATION OF MHD IN THIN CELL ELECTRODEPOSITION
}

\author{
C. Cronemberger ${ }^{1,2}$, R. Ballou ${ }^{1}$, P. Molho1 ${ }^{1}$ \\ 1 Institut Neel, CNRS - UJF, BP166, 38042 Grenoble Cedex 9, France \\ ${ }^{2}$ CBPF, Rua Xavier Sigaud, 150, 22290-180, Rio de Janeiro, Brazil
}

\begin{abstract}
We are studying the effect of a magnetic field normal to the cell in electrodeposition of zinc arborescences. When the cell thickness is reduced, the MHD convection, responsible for morphology changes, spiraling, etc. is suppressed, but in a high magnetic field there is still an effect maybe due to small-scale hydrodynamic convection or to the Lorentz force on the growing metallic branches, the "Laplace" force.
\end{abstract}

Introduction. Thin cell electrodeposition under magnetic fields normal to the plane of growth often gives rise to spiral and dissymmetric arborescent patterns [1-4]. Low field experiments have shown that the mechanical effect of MHD convection is responsible for these features. Reducing the cell thickness, and thus the convection, decreases and even suppress spiraling [5].

In order to go further, we performed high magnetic fields experiments. We expect to observe field effects even in very thin cells, where the fluid motion, at least as a global convection, seems inhibited. One can also expect the growths to be slower and less destructive, since performed at lower voltage, but still presenting magnetic field effects on the growth processes. Changing the magnetic field range may also allow to discriminate between the MHD effect induced by the Lorentz body force and the direct force on the conducting branches.

In fact, high field experiments in very thin cells, where no global convection is observed, still show a strong effect of the magnetic field on the morphology (branch thinning, proliferation, disorder). In order to check if a small-scale hydrodynamics could explain such field effects on the morphology, attempts are made to characterize the hydrodynamics of the system.

Experiments. Experiments are electrodeposition of zinc arborescences in thin cells, in a range of voltage and initial concentration leading to dendritic growth. The experimental cell consists in a copper circular anode, whose thickness defines the cell thickness, and a point cathode, which is a thin copper wire at the center of the cell. Two plates enclose the electrolyte, a $\mathrm{Zn}\left(\mathrm{SO}_{4}\right)$ aqueous solution. A constant voltage is applied between the electrodes, and metallic Zinc, in shape of arborescence, deposits at the cathode. A schematic representation of the experimental cell is shown in Fig. 1. All experiments presented here were performed using an applied voltage of $7 \mathrm{~V}$ and an initial concentration of $0.3 \mathrm{M}$. The magnetic field, normal to the cell, is applied using a superconducting coil, and we present here results obtained between 0 and $6 \mathrm{~T}$.

The cell thickness is a key parameter. We used cells of thickness 50, 25 and $15 \mu \mathrm{m}$, defined by the thickness of the ring anode when the top cover is flat. In very thin cells (25 and $15 \mu \mathrm{m}$ ), it is difficult to check whether MHD convection is still present or not. We have tried to use small particles of a rheological fluid to visualize the small-scale hydrodynamics, together with the growth of the aggre- 

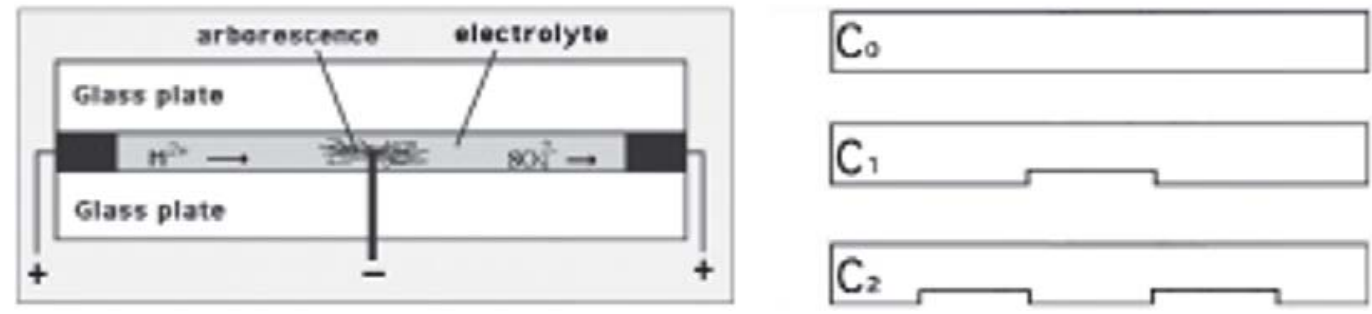

Fig. 1. Experimental cell. Three types of top cover were used. $\mathrm{C}_{0}$ is flat, while $\mathrm{C}_{1}$ and $\mathrm{C}_{2}$ present steps of $100 \mu \mathrm{m}$ thick, allowing a variation of the cell thickness along the radius.

gates. The results are not conclusive, and we cannot say that it helps to visualize the fluid motions. In order to evidence the thickness effect on the convection and morphology, we used also other types of top cover, named $\mathrm{C}_{1}$ and $\mathrm{C}_{2}$ (Fig. 1 ). They define different cell shapes, allowing a non-uniform thickness, function of the cell radius. The flat top cover was made of glass or plexiglas, while the non-flat cover was exclusively made of plexiglas.

Macroscopic and microscopic observations. We present in Fig. 2 images recorded during the growth for cell of thickness $25 \mu \mathrm{m}$, for different values of the magnetic field. The "macroscopic" images (Fig.2, top panel) are obtained using a camera and an objective. The size of these images corresponds to $22 \times 16.5 \mathrm{~mm}^{2}$.

In zero fields, the growth is dendritic, with few branches, rather thick and well-ordered. Under the field, the branches are thinner, more disordered, and branches' proliferation gives an impression of non-dendritic growth. One observe spiraling, even if sometimes less visible.

We also performed microscopic observations during the growth under high magnetic fields, using a Questar long working distance microscope, able to give a resolution of few $\mu \mathrm{m}$. The microscopic images (Fig. 2, bottom panel) correspond to $1.8 \times 1.4 \mathrm{~mm}^{2}$.

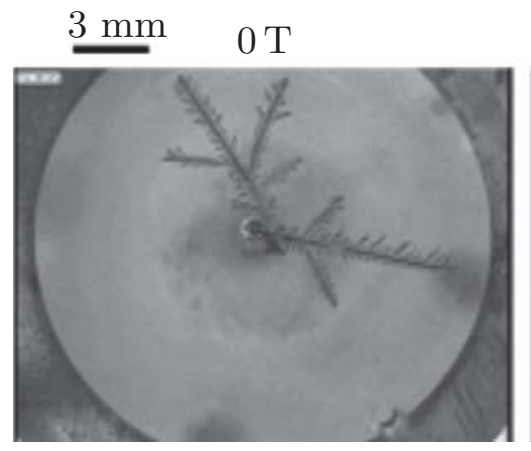

$300 \mu \mathrm{m} \quad 0 \mathrm{~T}$

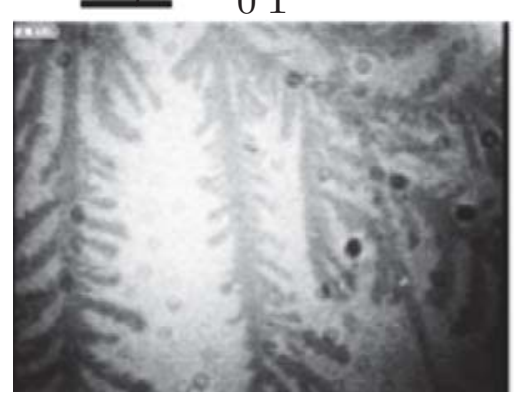

$4 \mathrm{~T}$

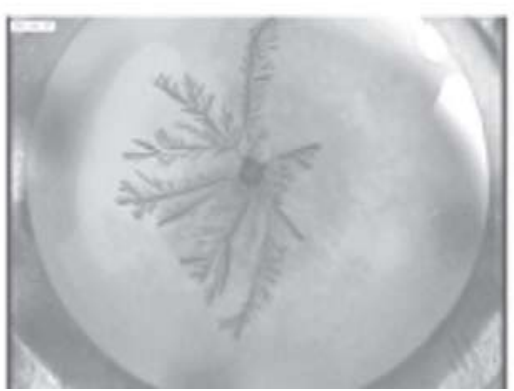

$4 \mathrm{~T}$

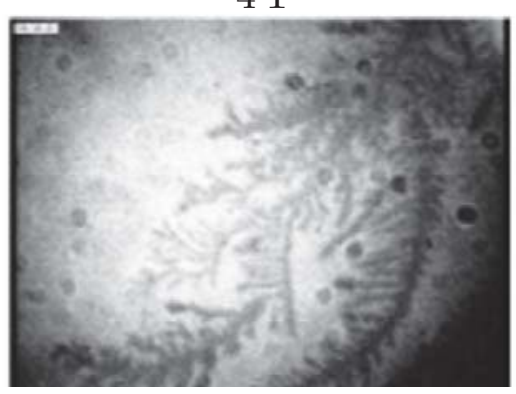

$6 \mathrm{~T}$

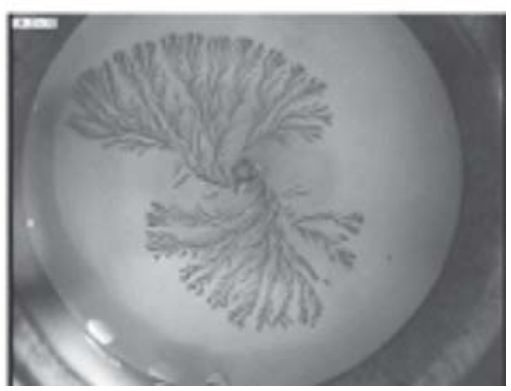

$6 \mathrm{~T}$

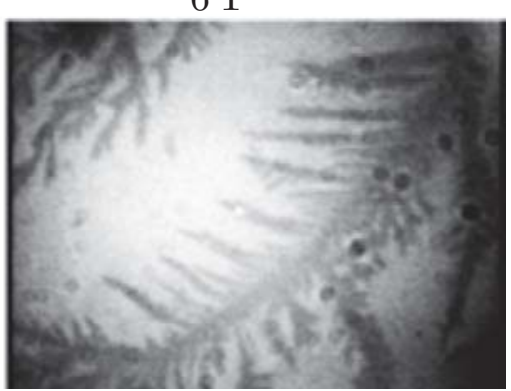

Fig. 2. Macroscopic views of growths in a $25 \mu \mathrm{m}$ thickness cell with a flat cover, for magnetic field values 0,4 and $6 \mathrm{~T}$. 

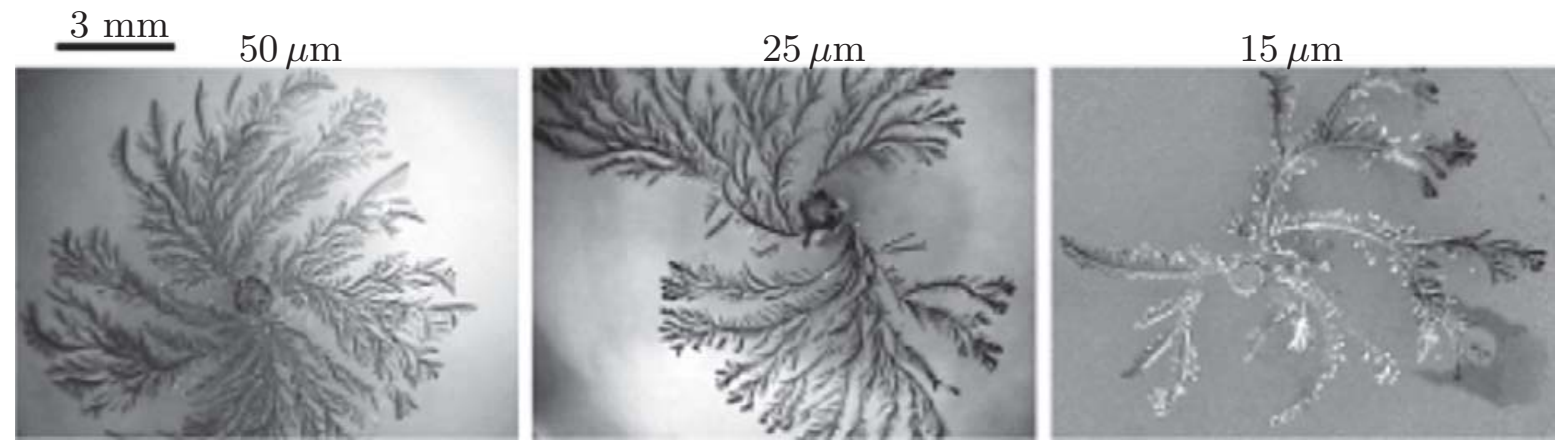

Fig. 3. Growths under $H=6 \mathrm{~T}$, for cell thicknesses 50, 25 and $15 \mu \mathrm{m}$, flat cover.

At a microscopic scale, it appears that the branches are still dendritic when grown under a magnetic field. Compared to zero field growth, they are thinner, more disordered, and spiraling is generally observed as a progressive bending of the branches.

We present in Fig. 4 a comparison between growths under $6 \mathrm{~T}$ for different cell thicknesses. Experiments with no magnetic fields show analogous results for growths in cells of thickness 50,25 and $15 \mu \mathrm{m}$. The well-ordered dendrites are just thinner and grow faster when the thickness is reduced. When a $6 \mathrm{~T}$ magnetic field is applied during the growth, the field effect depends on the thickness (Fig. 3).

At $50 \mu \mathrm{m}$, a global MHD convection is observed. The resulting pattern is ramified, with many disordered branches, and spiraling. At $15 \mu \mathrm{m}$, the pattern is quite different. The global MHD convection is no more observed. The pattern is spiraling, but smoothly, by a progressive rotation of the growing branches, quite different from the observations in thick cells, where spiraling was the result of the strong global convection, breaking the branches and nucleating new ones [5]. Also, the growth at $15 \mu \mathrm{m}$ remains dendritic at a macroscopic scale. The $25 \mu \mathrm{m}$ pattern is an intermediate case.

Electrical current variations measurements. We also performed current measurements during the growth, which may be a tool to characterize the growth processes. The integrated current is a measure of the deposited mass, and its variations reflect the conductivity of the aggregate, influenced by the morphology, the number and the shape of the branches, the nucleation of new branches, etc. Examples of current measurements, for different magnetic fields and thicknesses, are presented in Fig. 4.

Fig. 4. Electric current variations during the growth for cell thicknesses of 50,25 and $15 \mu \mathrm{m}$, and magnetic field values of 0 (grey curves) and $6 \mathrm{~T}$ (black curves).

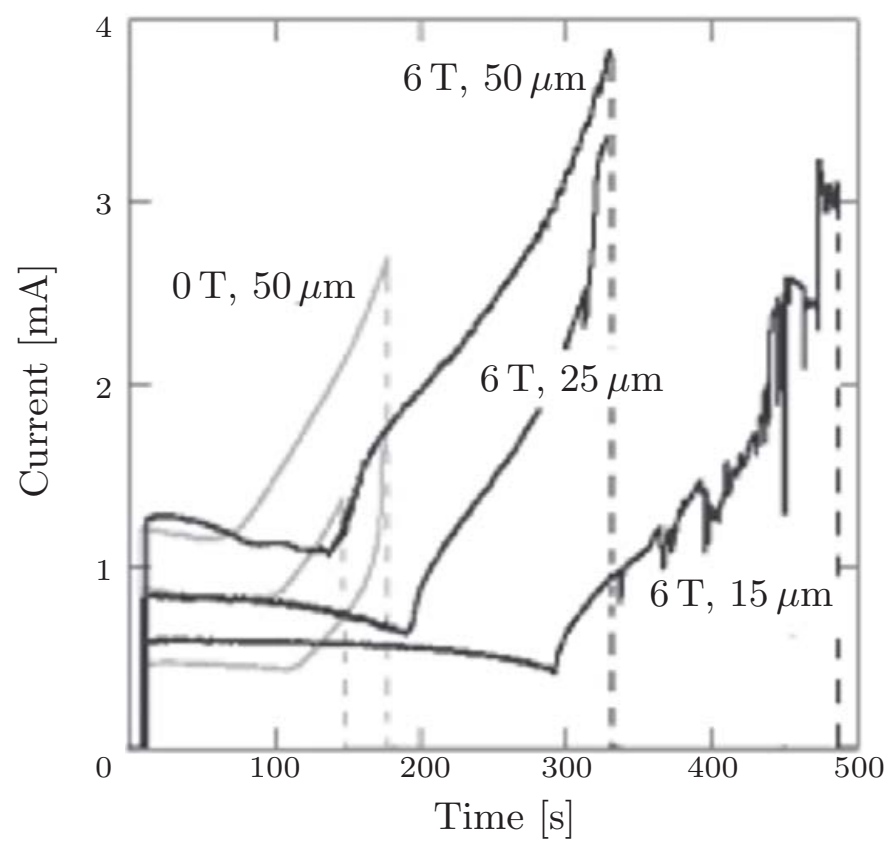


In zero fields, when a constant voltage is applied between the electrodes, the electric current begins to decrease from an initial value. After a short time, the current starts increasing regularly that corresponds to the beginning of the growth of the arborescence. The behaviour is similar for different values of the cell thickness; only the initial current value and the time before the beginning of the growth are modified (grey curve in Fig. 4).

When a $6 \mathrm{~T}$ field is applied, the initial current value is unchanged, but the current decreases during a longer time before the growth starts. The current variation during the growth is less regular, with slope changes, and eventually noisy variations (black curves in Fig. 4).

To summarize the observations of the current variations, the initial current value depends on the cell thickness, but not on the field value. The time before the growth starts is larger when the cell thickness is reduced, and smaller in zero fields than under a field of $6 \mathrm{~T}$. It is not clear experimentally if one can define a characteristic value (for a given thickness and field value) of the current necessary for the growth to start. The shape of the current variation seems characteristic of the presence or not of a magnetic field during the growth. The current variations show field effects before the growth starts, even in very thin cells, where MHD convection is not visible, suppressed or very slow.

1. Non-uniform cell thickness. The use of cells with non-uniform thickness is a way to vary the "initial conditions" to observe the effects of hydrodynamics on the growth. Two types of cell cover were used beside the flat one. They are schematically represented in Fig. 1. The "cell thickness" with such covers corresponds to the thinner part of the cell.

In cells with $\mathrm{C} 1$ cover, the growth starts in a thick zone, and then reaches a thinner one. Fig. 5, left part, shows two examples of such growths, $0 \mathrm{~T}$, cell thickness $25 \mu \mathrm{m}$, and $6 \mathrm{~T}$, cell thickness $50 \mu \mathrm{m}$. Growths with no magnetic fields are quite analogous for the different cell thicknesses. In the thick zone, rather dense dendrites grow slowly. When entering the thin zone, few thin dendrites emerge and grow fast, spanning to fill the empty space with thin branches.

When a $6 \mathrm{~T}$ field is applied, 50 and $25 \mu \mathrm{m}$ cells behave in the same way: in the thick zone, the growth is compact and perturbed by the MHD convection by a "typical" strong hydrodynamic effect: breaking of branches and nucleation of new branches, local spiraling at the tip. When the thin zone is reached, few thin dendrites emerge, which are then affected, leading to proliferation and spiraling. The $15 \mu \mathrm{m}$ cell leads to growth analogous to the $25 \mu \mathrm{m}$ one in the thick zone, less perturbed, but the growth is then inhibited and does not reach the thinner part of the cell.

In cells with the $\mathrm{C}_{2}$ cover, the starting zone is thin, and then the branches enter a thick one. Fig. 6, right part, shows four examples of such growths: $50 \mu \mathrm{m}$, 0 and $6 \mathrm{~T}, 25 \mu \mathrm{m}, 0 \mathrm{~T}$ and $15 \mu \mathrm{m}, 6 \mathrm{~T}$. They illustrate the effects of the thickness and the magnetic field on the growth. In zero fields, the $50 \mu \mathrm{m}$ cell leads to few thin dendrites growing rather fast in the thin zone, slowing down and becoming thicker when entering the thick zone. 25 and $15 \mu \mathrm{m}$ cells behave in the same way: thin ordered dendrites grow fast and straight in the thin zone, slow down and become denser when they reach the thick one. Then waves of dissolution affect the already grown dendrites in the thin zone, followed eventually by the growth of new thin dendrites in the free space.

When a $6 \mathrm{~T}$ field is applied during the growth in the thin zone of the $50 \mu \mathrm{m}$ cell, the growths are rather thin, spiraling. When entering the thick zone, they are strongly perturbed, destroyed from the tip, which is a typical behaviour resulting 


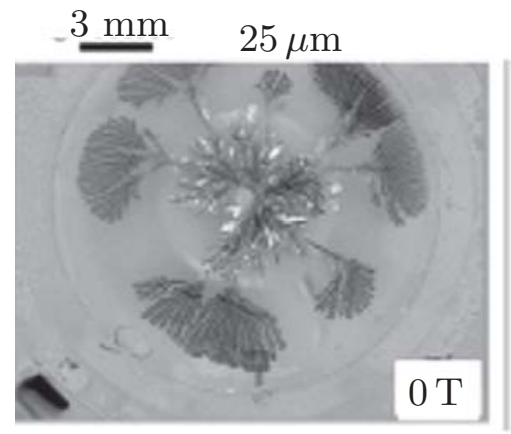

$50 \mu \mathrm{m}$

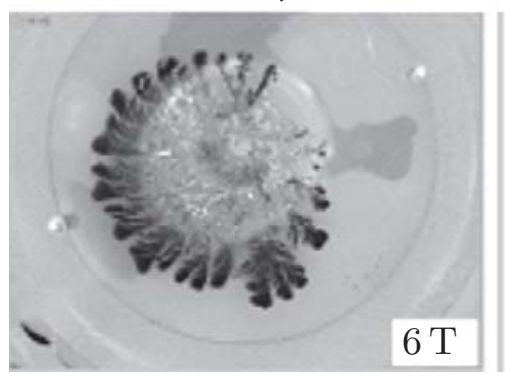

$\mathrm{C}_{1}$
$50 \mu \mathrm{m}$

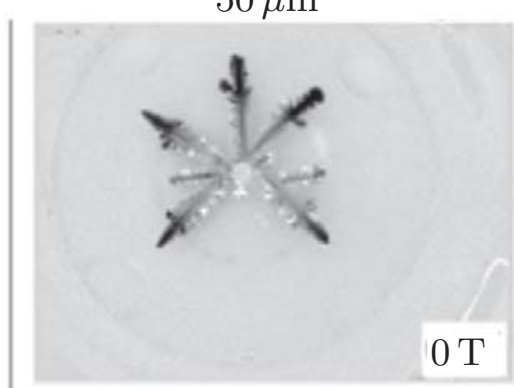

$50 \mu \mathrm{m}$

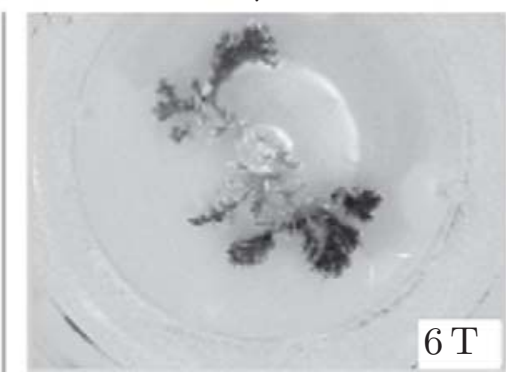

$\mathrm{C}_{2}$

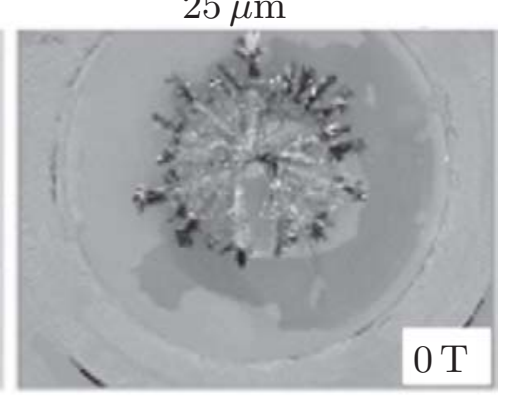

$15 \mu \mathrm{m}$

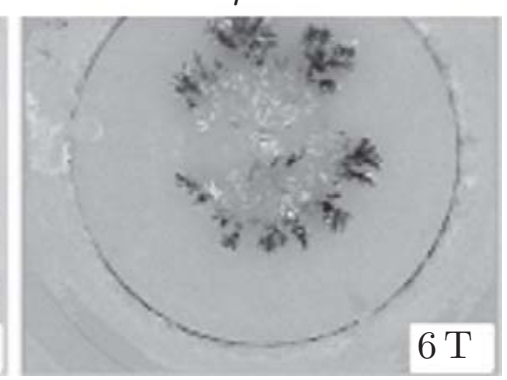

Fig. 5. Growths using the cell cover $\mathrm{C}_{1},(H=0$, cell thickness $25 \mu \mathrm{m}$ and $H=6 \mathrm{~T}$, cell thickness $50 \mu \mathrm{m})$, and the cell cover $\mathrm{C}_{2},(H=0$, cell thickness 50 and $25 \mu \mathrm{m}, H=6$ $\mathrm{T}$, cell thickness 50 and $15 \mu \mathrm{m})$.

from a strong hydrodynamic effect. The 25 ?m cell behaves in a similar way with, in addition, dissolution of the thin part when the branches enter the thick zone. Concerning the $15 \mu \mathrm{m}$ cell, very thin dendrites are observed in the thin zone. They grow fast, curved, with more branches than in zero field. In the thick zone, hydrodynamic effects at the tip are observed, leading to dense, perturbed growth, and to dissolution of the dendrites in the thin zone like in the $25 \mu \mathrm{m}$ cell case.

Those experiments using special top covers for the cell help to evidence the characteristic effects of the hydrodynamics on the growth processes, especially when the branches enter a thick zone. They also give some insights on the effect of the cell thickness on the morphology, even if globally the growths are more complicated. Dissolution processes are enhanced compared to uniform cells, especially when the growth regime changes. When the thickness is large, global convection is observable, strongly affecting the growth. When the thickness is small, the hydrodynamics is difficult to evidence and characterize.

Conclusion. In conclusion, decreasing the cell thickness suppresses or reduces MHD convection, but there are still high magnetic field effects (proliferation of branches, disorder and spiraling). Microscopic observations show that the morphology is still dendritic, thinner and more disordered, but does not show small-scale hydrodynamics. Using cells with non-uniform thickness gives rise to complicated phenomena (complex hydrodynamics, dissolutions ...), but shows the effects of thickness and field on the morphology locally. Concerning the process of growth, when strong hydrodynamic effects are observed, they are local, leading to branch breaking and nucleation, local spiraling of the native branches at the tip. In very thin cells there is no evidence of such hydrodynamic effects, spiraling is very smooth, obtained by a continuous rotation of the growing branches. No small-scale motion at the branch tip is observed. Electric current variations during the growth could give information, especially when correlated to growth observations. 
We have not yet answered to the origin of field effects in high field and very thin cells, but accumulating data gives a better insight on what is going on. For instance, even if it is possible that "Laplace" forces on the branches are becoming more relevant than MHD convection in very thin cells, one observes effects of the field even before the growth starts, which of course cannot be attributed to "Laplace" forces.

The microscopic observations and the analysis of the current variations during the growth are still in progress. We also plan to perform experiments varying the magnetic field during the growth. Such experiments should give a better insight on the beginning of the process affecting the morphology (fluid motion and branch deformation), but they are not simple since field changes in a superconducting coil take time. Numerical simulation is another way we are exploring to clarify the processes involved in this complicated experimental system.

Acknowledgement. Experiments in high magnetic fields were performed at CRETA, Grenoble. We also acknowledge the help of G. Souche, involved at the beginning of the high field experiments.

\section{REFERENCES}

[1] I. Mogi, S. Okubo, And Y. NAkAgawa. Dense radial growth of silver metal leaves in a high magnetic field. J. Phys. Soc. Jpn., vol. 60 (1991), no. 10, pp. 3200-3202.

[2] I. Mogi, M. Kamiko, S. Okubo, and G. Kido. Pattern formation of electrodeposit of zinc in magnetic fields. Physica B, vol. 201 (1994), pp. 606-610.

[3] I. Mogi, M. Kamiko, and S. Okubo. Magnetic field effects on fractal morphology in electrochemical deposition. Physica B, vol. 211 (1995), pp. 319322 .

[4] J.M.D. Coey, G. Hinds, And M.E.G. Lyons. Magnetic-field effects on fractal electrodeposits. Europhys. Lett., vol. 47 (1999), no. 2, pp. 267-272.

[5] V. Heresanu, R. Ballou, and P. Molho. Electrochemical growth of Zn and Fe arborescences under normal magnetic field. Magnetohydrodynamics, vol. 39 (2003), no. 4, pp. 461-468. 